\title{
The achievements of the Public Employment Policies
}

\author{
CHAKIR Said ${ }^{1}$ and KORCHI Mohamed Amine ${ }^{2}$ \\ ${ }^{1,2}$ Research Team in Finance and Accounting Management, \\ Faculty of Economic and Social Legal Sciences Kénitra, \\ Maamora University Campus BP: 2010, \\ Kenitra, Morocco
}

\begin{abstract}
At a time when developed countries have launched the design process and implementation of public policies targeting youth, other countries, however, do now have no specific policy for youth. Moreover, even for those who have developed this new form of legislation, it often remains inadequate and approach does not allow it to meet all the challenges that are faced youth.

Morocco is unfortunately ranked among the latter category that has its assets as the absence of any strategy in the production of tools to facilitate the systematic treatment of issues specific to youth and low involvement of stakeholders and the lack of crosscutting consult widely on the subject.

The prospects of the development of Morocco and the success of socio-economic changes dépondent conditions of socialization and development of the young generation, therefore, the implementation of sound public policy for young people regardless of the region their social and material status, gender, education and the nature of their business has become an urgent necessity.
\end{abstract}

Keywords: Public Policies, Employment, Unemployment, Innovation.

\section{INTRODUCTION}

Morocco has embarked on a very ambitious investment program: the planned investment for the five major sectors amounts to 5.6 billion euros for the period from 2008 to 2020.

Morocco's development prospects and the success of socio-economic changes depend on the conditions of socialization and development of the younger generation, thus the implementation of a solid public policy for young people regardless of their region their social and material status, their sex, their education and the nature of their activity has become a pressing necessity.

The challenge of this communication is the development of appropriate public policies for the development of innovation in Morocco. 1. The Morocco Innovation Initiative:

To develop a global vision of innovation in Morocco and give it a new impetus, the Ministry of Industry, Trade and New Technologies and the Ministry of Higher Education, Training of Managers and Scientific Research (MENSFCR) launched a participatory reflection called "Morocco Innovation Initiative" in order to define a pragmatic action plan.

This initiative is part of a larger project whose goal is to provide a vision for socio-economic actors in Morocco. In this context, the government has launched several sectoral plans and strategies, such as: Emergence, Azur, Halieutis, etc. (Figure 1). 


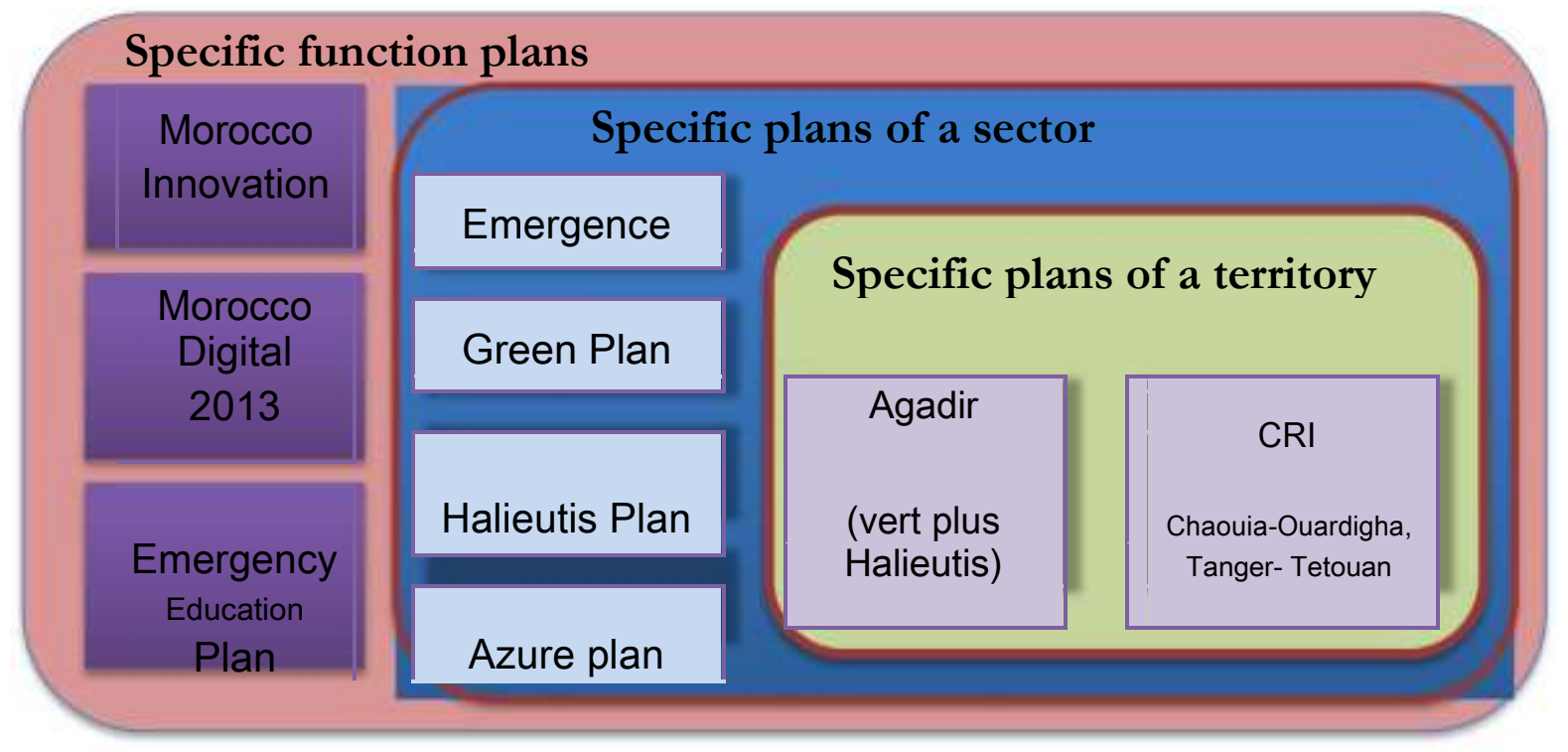

Figure 1: Implementation of the policy framework in Morocco

The Morocco Innovation Initiative is a cross between these sectoral strategies. It attempts to build an innovation ecosystem that would provide a horizontal framework to ensure that the plans mentioned would have maximum impact. The initiative was developed through a participatory approach with representatives of the main components of the innovation ecosystem (administrations, universities, research centers, businesses, civil society and the financial sector). Gaps have been identified along the innovation chain and a set of actions and measures has been designed to address them. The strategy document sets the following objectives to be achieved in 2014 : 1,000 patents per year and 200 innovative start-ups per year. Political priorities have been defined to address four major challenges :

1- Strengthen the competitiveness of Moroccan companies through innovation,

2- Allow Morocco to produce technology,

3- Exploit the R \& D capabilities of Moroccan universities,

4- Make Morocco attractive for talent and R \& D projects and foster a culture of innovation and entrepreneurship.

Four main axes were broken down into thirteen sites.

Table $n^{\circ} 1$ : Main components of the "Morocco Innovation Initiative"

\begin{tabular}{|l|l|l|}
\hline \multicolumn{1}{|c|}{ Axes } & \multicolumn{1}{|c|}{ Sites } & \multicolumn{1}{c|}{ Instruments, organisms } \\
\hline $\begin{array}{l}\text { And framework } \\
\text { Infrastructures }\end{array}$ & $\begin{array}{c}\text { Public/private governance of the initiative } \\
\text { A dedicated reception and orientation } \\
\text { structure }\end{array}$ & $\begin{array}{c}\text { Creation of a National Committee of } \\
\text { innovation } \\
\text { The Moroccan center of innovation }\end{array}$ \\
\hline Financement \& support & $\begin{array}{l}\text { Technological infrastructures Technology } \\
\text { transfert infrastructures Clusters }\end{array}$ & $\begin{array}{l}\text { Establishment of Cities of } \\
\text { Innovation in some universities } \\
\text { Framework policy for clusters }\end{array}$ \\
\hline $\begin{array}{l}\text { Develop a portfolio of products supporting } \\
\text { innovation } \\
\text { Stimulation of the venture capital system } \\
\text { Development of the intellectual property } \\
\text { market } \\
\text { Mobilization }\end{array}$ & $\begin{array}{l}\text { Mobilization of international funds for } \\
\text { innovation }\end{array}$ & $\begin{array}{l}\text { Horizontal measures of support for } \\
\text { funding }\end{array}$ \\
\hline $\begin{array}{l}\text { Creation of the Moroccan club of } \\
\text { innovation } \\
\text { Promotion of the culture of innovation } \\
\text { Positioning Morocco's R\&D and innovation } \\
\text { supply }\end{array}$ & \\
\hline
\end{tabular}

Source: The consultant of the SCF 
Innovation strategies have resulted in a series of support measures related to the knowledge-based approach. The infrastructure axis includes support infrastructure (transfer offices, training of support staff). In the area of the economy and incentives, several horizontal measures have been adopted in favor of financing which, in the field of innovation, remains one of the most problematic.

Other support mechanisms include support for sectoral innovation in the manufacturing industry, support for innovative start-ups, including Gazelles, support for venture capital and, finally, support for the creation of favorable innovation climate (eg road shows, awareness campaigns) and support for innovative use of standards. Other measures include tax incentives for the diffusion of innovative technologies, products and services, innovation awards such as the design award, advice and financial incentives for the use of intellectual property rights, Outreach and other measures to provide general information on IPR-Intellectual Property Rights.

Finally, the dimension of R \& D cooperation (joint projects, PPP-Public-Private Partnership-with research institutes) appears as an important dimension, as does the transfer of knowledge (research contract, patents and IPR-related issues). Public, academic and non-profit institutes).

This innovation initiative has targeted four areas of research and advanced technology to help Morocco to offer one of the most competitive R \& D offerings in the region and place it in the world average for : biotechnology, ICT, materials, nanosciences and nanotechnologies.

The authorities count on the realization of innovation cities (3 pilot cities launched in 2011: Fez, Rabat and Marrakech and 10 planned later) According to the Ministry of Economy and Finance, these 3 cities will mobilize up to 200 million dirhams, the establishment of a technical and financial expertise for the financing of research and development. innovation in Morocco, easier access for Moroccan companies and research organizations to European innovation programs, the creation of a fund to support innovative projects by individuals following the creation of companies and, more generally, assistance to entrepreneurship in the field of innovation. As a result, private financing is expected to increase significantly by 2025 , reaching more than $25 \%$ of total $\mathrm{R}$ \& D funding;

Table ${ }^{\circ}$ 2: Growth forecasts

and balance of public / private financing of R\&D in 2025

\begin{tabular}{|l|l|l|}
\cline { 2 - 3 } \multicolumn{1}{l|}{} & $\mathbf{2 0 1 0}$ & $\mathbf{2 0 2 5}$ \\
\hline $\begin{array}{l}\text { Expected evolution of funding R\&D } \\
\text { in \% on GDP }\end{array}$ & $1 \%$ & $2 \%$ \\
\hline $\begin{array}{l}\text { Expected evolution of funding Public } \\
\text { and private }\end{array}$ & $\begin{array}{l}\text { Public funding }>75 \% \\
\text { Private funding }<75 \%\end{array}$ & $\begin{array}{l}\text { Public funding }<25 \% \\
\text { Private funding }>25 \%\end{array}$ \\
\hline
\end{tabular}

Source : A. BENJOUAD "Environment conducive to innovation. Moroccan Experience » CNRST, CODIST-I, Addis Ababa, April 28May 1, 2009

To date, several achievements can be listed: concerning the performance, the Academy Science \& Technology initially focused on science has gradually become interested in the transfer of knowledge and technologies (TCT) placing knowledge at the heart of the issues. Therefore, government funding for research is no longer available to promote the TCT (for example, funds of telecom operators, CNRST, R\&D Morocco, etc.) The Ministry of Higher Education's emergency plan includes a a significant research component to strengthen the structure of university research and increase R\&T assistance to infrastructures and services (UATRS, IMIST, MARWAN) whose objectives are as follows:

1- Improvement of internal returns to higher education,

2- Improve employability,

3- To encourage talent and innovation in the field of scientific and technological research,

4- take advantage of the discoveries of scientific research,

5- Upgrade and motivate human resources by establishing a culture of monitoring and evaluating progress, 
6- Develop a master plan for higher education, in order to increase the autonomy of universities and to set up a contractual system, covering multi-year contracts for academic staff.

More support for R\&D is available to businesses. And finally, the diaspora provides a growing contribution.

The development of innovation clusters (software, information technology, microelectronics and biotechnology) has led the younger generation and university professors to create new models of start-ups and spin -offs based on innovation. This raises the question of the adherence of critical mass to such models and the autonomous development of innovation poles. This has also enabled the diffusion of technology in services (high value-added tourism), agro-industry (Agadir in Morocco, for example) and industrial clusters. The development of these poles is characterized by the export and the creation of jobs. The development of gateway institutions and poles is linked to the environment.

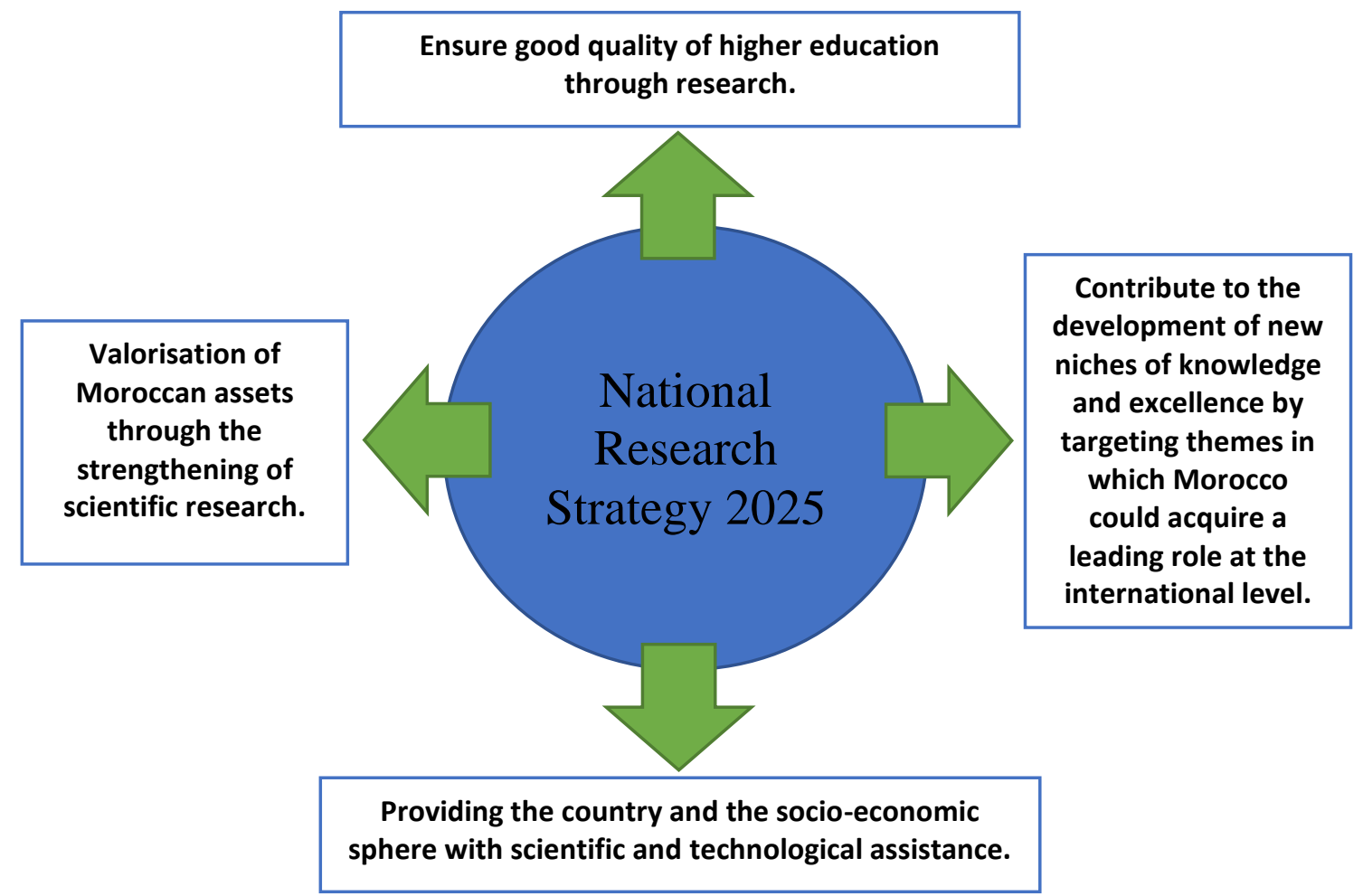

Figure 2 : Direction of the Research Strategy 2025

Source : A. BENJOUAD "Environment conducive to innovation Moroccan experience" CNRST, CODIST-I, Addis Ababa, April 28- May 1, 2009

\section{MOROCCO NUMERIC 2013}

The new strategy "Morocco Numeric 2013" (MN2013) adopted by the Moroccan Government in 2008, pursues some of the objectives set by the previous strategy given the growing importance of the IT sector : it represents $7 \%$ of the GDP, 25\% of the growth and $60 \%$ (For the information society and the digital economy) of employment. MN2013 aims to extend the use of Information and Communication Technologies (ICT) by the public, government and businesses from 2008 to 2013 with an investment of 5.2 billions DH. The human capital objective is to reach 30,000 IT-trained profiles for 2008-2013 and 3,000 offshoring (IT) profiles as part of the EMOP until 2013 (Data provided by the Ministry of Economy and Finance).

MN2013 is structured around four strategic priorities, the first three of which are :

To make broadband Internet accessible to citizens;

To bring administration closer to user needs through an ambitious e-government program; 
International Journal of Advances in Scientific Research and Engineering (ijjasre), Vol 5 (4), April 2019

\section{3- ENCOURAGE THE COMPUTERIZATION OF SMES AND DEVELOP THE SECTOR BY PROVIDING SUPPORT TO LOCAL ACTORS.}

Central to this strategy are efforts to ensure that one in three Moroccan families (rather than one in 10 in 2008) will have a high-speed Internet connection in 2013, with priority given to young people. To this end, some 400 computer centers will be built in disadvantaged and remote areas and more than 80,000 technical school engineering students will receive laptops with Internet access.

The strategy also aims to generate an additional GDP of DH 7 billion and create 26,000 jobs in 2013 in addition to the forecast of 90,000 from off-shore activities. According to the Ministry of Finance and the Economy, offshoring is expected to create about 70,000 additional jobs over the period 2009-2015. Income is expected to double in 2012 to 60 billion dirhams, with a small portion (1.8 percent) coming from ICT exports excluding offshoring activities. The number of start-ups should increase with the creation of 100 new ones.

\section{4- FOSTER THE EMERGENCE OF CENTERS OF EXCELLENCE WITH HIGH EXPORT POTENTIAL.}

This is the first document explicitly integrating innovation as one of the key elements of the strategy. In 2009, the Government of Morocco set up a national fund for innovation in the field of ICT with an initial investment of 100 million DH. This fund is managed by the CGC (Central Guarantee Fund) and was created in partnership with a professional association called Apebi, the Federation of IT Professionals. Half of this funding is focused on innovative projects carried out by Moroccan companies in the ICT field, while the other half is supposed to be paid for by the companies themselves. The repayment period is six years with the possibility to defer payments up to three years, at an annual interest rate of $2 \%$ (excluding VAT). The Moroccan Government hopes to set up 15 ICT clusters in 2013 with a budget of 62 million dirhams. This dimension of innovation is reinforced by Maroc Numeric Cluster (MNC).

MNC is a joint initiative of the Ministry of Industry, Trade and New Technologies and several key players in the ICT field. These include telecommunications operators, companies, research and training institutions and associations. Its goal is to unite all these actors around a common vision in order to facilitate and promote innovation in the field of ICTs in Morocco. In this regard, it defines four main objectives as part of the "MNC 2013" vision :

1- adapting ICTs to human development through innovation and increased ownership of ICT innovation by citizens,

2- make ICT a source of productivity and added value for other sectors economic, public and private sectors through SAAS products (software as a service) and cloud initiatives for businesses and contribute to Green IT programs,

3- make ICTs one of the pillars of the economy, mainly by contributing to innovation through offshoring,

4- position Morocco as a regional technological hub by connecting Moroccan innovation internationally and by acquiring regional leadership.

MNC's ambition is to become a reference cluster in the region through its various missions to promote high-content, joint and collaborative projects within identified poles of excellence, by creating an appropriate technological environment, a synergy in favor of innovative projects and the emergence of innovative start-ups. It also aims to enhance the competitiveness of companies within the cluster, to win foreign markets, promote support and advice to project leaders and enhance the visibility of Moroccan innovation on the international scene. MNC defines five major commitments:

1- develop the cluster and its ecosystem,

2- develop innovative projects,

3- better mobilize the skills of the ICT sector,

4- facilitate access to the Moroccan market for innovation,

5- connect Moroccan innovation internationally.

Four programs are defined for this purpose:

1- "Innov resources",

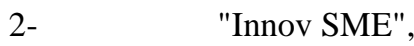

3- "International connect",

4- IT".

Four poles of excellence are then identified: 
International Journal of Advances in Scientific Research and Engineering (ijjasre), Vol 5 (4), April 2019

$1-$

2-

3-

4-
Mobile services,

Security, electronic banking, digital rights,

Multimedia,

Local software package.

The committed players include the Casablanca Technopark, initiated by the ONA Group on a public-private partnership basis and managed by the Moroccan Information Technopark Company (MITC), and the Bouznika Technopole. The Casablanca Technopark is part of the strategy

Morocco to support entrepreneurship and innovation in the country through startups and incubators. Since its creation, CasaTechnopark has strongly encouraged the development of the high-tech industry. More than 160 companies have been attracted since its beginnings in the years 2001-2007, including service to industry, startups and large companies and training centers. Thirty of them belong to returning expatriates. CT contributes significantly to employment with an average of 300 jobs per year. The creation of 200,000 jobs a year, 5\% of which are engineering and technical positions, is in prospect. Other maturing projects include the Technopolis of Rabat-Salé, and the agropoles of Marrakech, Agadir, Oujda and Fez.

\section{CONCLUSION}

According to the HCP, between the first quarter of 2013 and the same period of 2014, 89,000 jobs were created by the Moroccan economy, 46,000 in urban areas and 43,000 in rural areas, of which 85,000 have been for women. These creations constitute the balance between the 93,000 jobs earned by the "services" sector and 53,000 by "agriculture, forestry and fishing" and the losses of 45,000 jobs suffered by "industry including handicrafts" and 12,000 by the "BTP".

In this context, the number of unemployed in Morocco between the two periods increased by 114,000 people, 74,000 in urban areas and 40,000 in rural areas, reaching 1,191,000 people. The unemployment rate thus rose from $9.4 \%$ to $10.2 \%$, registering an increase of 0.8 points. In urban areas, it increased from $13.7 \%$ to $14.6 \%$ and in rural areas from $4.4 \%$ to $5.1 \%$. Among young people aged 15 to 24 , it was $20.2 \%$ instead of $19.5 \%$ and among degree holders, $17.5 \%$ instead of $16.5 \%$. Unemployment is at $29 \%$ due to dismissals or shutdown of the activity of employers.

The unemployment rate of non-graduates generally does not exceed 6\%, it remains high among graduates:

- higher level with $20.9 \%$, especially faculty graduates $23.3 \%$,

- average level with 16,1\%, in particular those of the professional qualification $20,9 \%$,

- Among urban young people aged 15 to 24 , it is $33.1 \%$ for males and $46.2 \%$ for females.

In addition, an analysis of the main characteristics of the unemployed labor force reveals that:

- more than three quarters of the unemployed $76.9 \%$ are urban,

- Six out of ten $60.1 \%$ are between 15 and 29 years old,

- One in four $25.5 \%$ is a graduate graduate,

- Almost half $45.6 \%$ are first-time jobseekers,

- Six out of ten $59.4 \%$ have been unemployed for more than a year.

The underemployment rate, for its part, fell between the two periods, from $8.6 \%$ to $9.5 \%$ at the national level, from $8.2 \%$ to $9.1 \%$ in urban areas and $9.1 \%$ in $9.9 \%$ in rural areas.

Despite the efforts made by different policies the unemployment rate remains unstable between 2010 and 2014 respectively 10.0-9.1-9.9 9.4-4.10.2.

On the other hand, the rate of underemployment decreased between 2010 and 2014 respectively 11.8- 12.0- 9.3-8.6-9.5.

According to the Court of Auditors the results explain a failure in the system between objectives and achievements (out of 89 projects only 25 are operational), this gives rise to projects that remain disabled, for lack of accompanying measure thus affecting the human capital (60\% remain not started according to the court of accounts). 


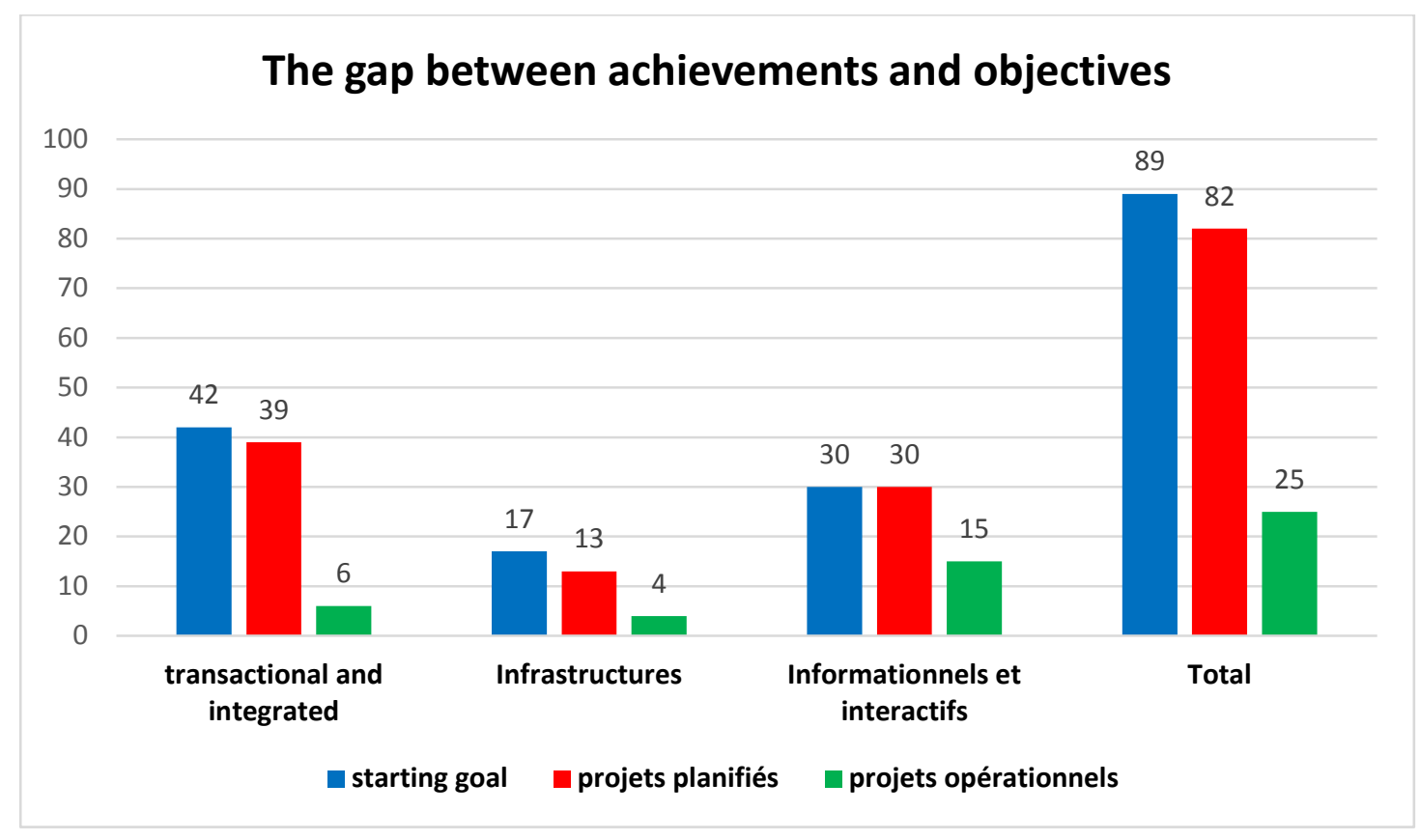

Figure 3. Bar graph of Achèvements and Objectives

Source : Courts of Accounts

\section{REFERENCES}

1. Abelkader DJEFLAT CMI Consultant, Morocco's Efforts in the Knowledge-Based Economy, September 2012, 95 pages.

2. Amine Bensaid "Context and Initiatives for Technology Transfer and Innovation in Morocco" Project Exploring Knowledge and Tech Transfer Opportunities in the Euro-Mediterranean, Bruxelles, 25-26 févr. 2010 Initiative www.mcinet.

3. Yassine Ouardirhi "Financing Innovation in Morocco" Ministry of Industry, Trade and New Technologies, Rabat 05 June 2011.

4. HCP labor market situation in the first quarter of 2014 .

5. Erawatch Initiative Morocco Innovation Authors / Responsible Body: Ministry of Industry, Trade and New Technologies http://erawatch.jrc.ec.europa.eu/erawatch/opencms/information/country_pages/ma/policydocument/policy doc_0005?tab=template\&country=ma

6. http://www.marocinnovation.ma/DocumentsRS/CMI/Initiative_Maroc_Innovation.pdf

7. Ministry of Industry, Trade and New Technologies,

http://www.mcinet.gov.ma/TechnologiesAvancees/PromotionInnovation/Pages/Initiative\%20Maroc\%20Innovation.aspx

8. ONA, (North African Open), spent 150 million for R \& D between 1999 and 2003 (Bouoiyour 2003).

9. The technopark of Casablanca http://www.casablanca-technopark.ma/typologie.asp

10. Aderrafie Hanouf talks about the technopark of Casablanca 08/10/2006

11. Moroccan information technopark company - MITC 2005

12. The Casablanca Technopark (PDF file)

13. High Commissariat au Plan, hcp labor market situation first quarter 2014

14. For the information society and the digital economy

15. Données fournies par le the ministère de l'Économie et des Finances

16. www.apebi.org.ma/index-eng.php

17. Magharebia http://www.magharebia.com/cocoon/awi/xhtml1/en_GB/features/awi/features/2008/10/26/ feature-01 2009$07-24$ 